Dear Colleagues:

This issue is the second dedicated (devoted) to the memory of Professor Jaime Retuert. For this occasion, Dr. Ekkehard Fluck, who was his PhD thesis Advisor in Stuttgart during the years 1970-1972, provided some words on behalf of Dr. Retuert.

Dr. Carlos Díaz Valenzuela

E D I T O R 


\section{In memory of Dr. Jaime Retuert de la Torre}

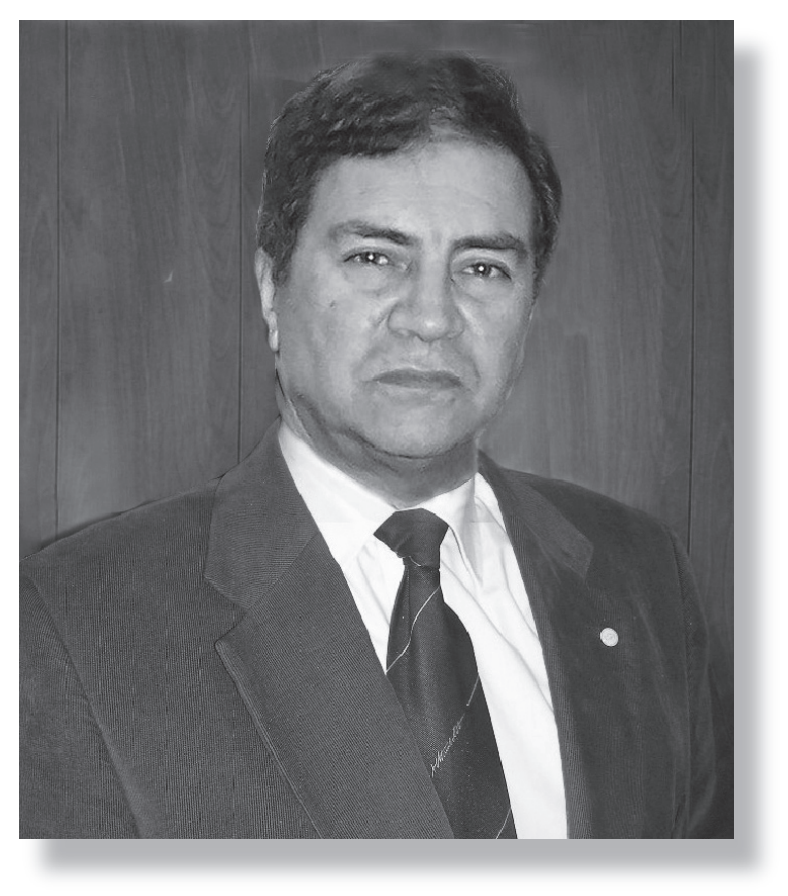

Recently, I learned with great regret that Professor Jaime Retuert de la Torre has passed away. We had known each other for more than forty years. During the sixties of the past century, I often visited the Universidad de Chile in Santiago. Then we were introduced by Professor José Edwards who unfortunately passed away early too. In that time, and by means from the German Academic Exchange Service, three doctorate German assistants had to be sent to Santiago.

As a result, there were twelve Chilean students of chemistry that after finishing their undergraduate studies had come to Germany to develop their doctoral thesis in my working Group at the University of Stuttgart, from where they were granted a Dr. rer. Nat. degree. Among them was Dr.Jaime Retuert, in the years 1970-1972. The title of his dissertation was: "Über Phosphorbetaine". The experience of having Chilean and German PhD students working together in my lab was very nice and unique.

In later years, I coincided many times with Prof. Dr. Retuert either in Chile or in Germany and I felt very pleased to know about his academic achievements in Chile. And now, I regret his decease that interrupted his work so early. However, what Dr. Retuert has done for chemistry, his university and students, remains alive. 


\section{PROF. PETR VANÝSEK}

Northern Illinois University

Department of Chemistry and Biochemistry

DeKalb, Illinois, United States

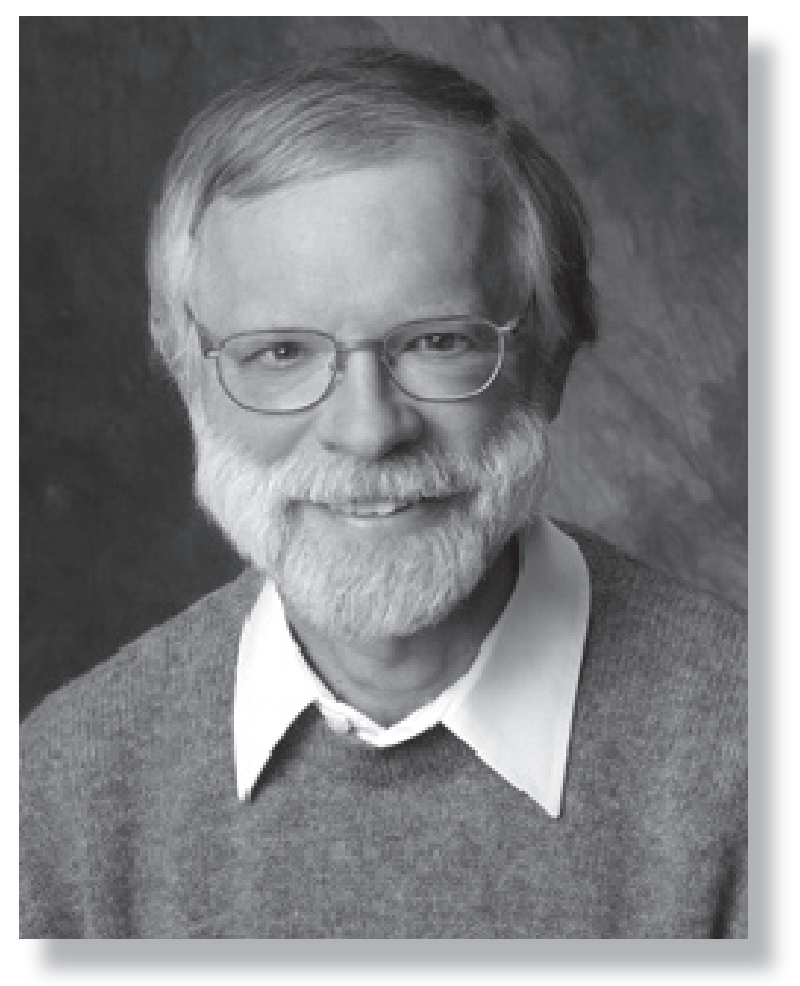

Dr. Petr Vanýsek, is an analytical faculty at the Chemistry and

Biochemistry Department at Northern Illinois University. His is an electrochemists and his interest are in electroanalytical chemistry, spanning from sensors to the studies of liquid/liquid interfaces. His interests are also in electrochemical instrumentation, namely impedance measurements and their proper interpretation. Through impedance studies he is also involved in applied aspects of electrochemistry - corrosion and fuel cells. Vanysek is the Secretary of the Electrochemical Society, Regional Representative (USA) of the International Society of

Electrochemistry and a board member of the Society for Electroanalytical Chemistry. 